\title{
Differential measures of 'sustained-attention' in children with attention-deficit/hyperactivity or tic disorders: relations to monoamine metabolism
}

\author{
Robert D. Oades, \\ 2000 Psychiatry Research, 93, 165-178 \\ This is the reformatted manuscript submitted - prior to publication in its final form at doi:10.1016/S0165-1781(00)00105-0 \\ University Clinic for Child and Adolescent Psychiatry, Virchowstr. 174, 45147 Essen, Germany.
}

\begin{abstract}
Controversy exists on whether the constructs tested by paper/pencil and computerized continuousperformance-tests (CPT) are similar, and the deficits recorded in children with attentiondeficit/hyperactivity symptoms (ADHD) are comparable. Signal-detection measures were recorded on four such tests of 'sustained attention', with increasing working-memory requirements in healthy children (14, mean 10 years), and those with $\operatorname{ADHD}(14$, mean 10 years) or a tic syndrome (TS, 11, mean 11 years). Clinical associations were sought from $24 \mathrm{~h}$-urinary measures of monoamine activity. The cancellation paper/pencil test revealed no group differences for errors or signal detection measures. On the CPT ADHD children made more omission and commission errors than controls, but TS children made mostly omissions. This reflected the poor perceptual sensitivity ( $d$-prime, $d^{\prime}$ ) for ADHD and conservative response criteria (beta) for TS children. This group difference extended to the CPT ax which was shown on a regression analysis to test for putative working-memory-related abilities as well as concentration. In all children immediate response-feedback reduced omissions, and modestly improved $d^{\prime}$. CPT ax performance related negatively to dopamine metabolism in controls and to serotonin metabolism in the ADHD group. But comparisons between the metabolites in the ADHD group suggest that increased serotonin- and decreased noradrenaline- with respect to dopamine-metabolism may detract from CPT performance in terms of d-prime. CPT tasks demonstrated a perceptual-based impairment in ADHD and response conservatism in TS patients independent of difficulty. Catecholamine activity was implicated in the promotion of perceptual processing in normal and ADHD children, but serotonin activity may contribute to poor CPTax (working-memory) performance in ADHD patients.
\end{abstract}

Key Words: attention, signal-detection, working-memory, continuous performance test dopamine, noradrenaline, serotonin

\section{Introduction}

The ability to sustain attention or concentrate is frequently measured with the continuous performance task (CPT). The task has two basic features: first, there is a discrimination between repeatedly presented stimuli (e.g. letters) based on a simple rule provided by instruction (e.g. the target is an ' $x$ '); second, it lasts long enough to allow the ascertainment of performance levels over a number of trials (e.g., accuracy and signaldetection measures). The development of these abilities in children has been studied for about 40 years: task instruction can regulate performance from about 5 years of age, with a major improvement occurring around 8 years (Luria, 1959; Sykes et al., 1973).
Childhood attention-deficit hyperactivity disorder (ADHD) is primarily characterized in the clinic by an unusual level of motor activity, impulsivity and attention-related deficits. The CPT performance of children with ADHD has been characterized by slower reaction times (Klorman et al., 1979), more errors of omission and commission (Sykes et al., 1971; Dykman et al., 1979), and changes of perceptual and response strategy (e.g., the decrease of signal-detection measures of $d^{\prime}$ / $d$-prime [less sensitive detection threshold] and beta-criterion [more liberal responsebias: Nuechterlein, 1983]). But the same type of performance decrement is recorded over time in normal and ADHD children (van der Meere and Sergeant, 1988). 
However, in the study of ADHD children interest and controversy has arisen over a) the best modality or task form to demonstrate performance differences, a matter of considerable clinical interest, $b$ ) the measure most impaired (e.g., omission vs. commission errors or detection thresholds vs. response bias), c) the nature of the intervening variable measured by different task forms (e.g., concentration [the ability to maintain signal detection performance over short periods without distraction] vs. working memory [WM: the ability to maintain a shortterm trace for relevant information]), d) the influence of reinforcement or feedback on performance, e) the contribution of brain regions and transmitter systems to function and dysfunction. These latter features are important both for an understanding of the underlying functions as well as for the planning of treatment.

In this report these 5 issues are approached with the study of three groups of children chosen to illustrate the specificity of the results: healthy children, those diagnosed with ADHD and children with tic disorders expressing symptoms of attentional deficit. First, performances on a paper/pencil vs. a computer modality are compared. Second signal detection measures are emphasized as they reflect the ability to remain on task in terms of stimulus detection ( $\left.d^{\prime}\right)$ and decide cautiously or liberally (beta-criterion), to minimize target omission or false-alarms. Third, performance on the CPTx is compared with that on the CPTax that introduces a WM component over and above the need to concentrate (i.e. respond to an $x$ only after the letter a). Fourth, the CPTax was repeated with immediate auditory feedback (different tones for a right or wrong response) as a contrast to the usual presentation of success at the end of a session. Lastly, as these tests formed part of a more extensive psychophysiology study, the indications for the general levels of mono-amine transmitter activity obtained from $24 \mathrm{~h}$ urine samples were examined for association with performance. The result here could both drive hypothesis testing in future research as well as providing a pointer for treatment.
The background and controversy to these five issues will be briefly described. In general, on tests of 'sustained attention' errors are likely to increase if the ADHD subjects are young (Sostek et al., 1980), male (Horn et al., 1989), academic achievement is poor (Campbell et al., 1991), the symptoms are severe (Klee and Garfinkel, 1983), the task is difficult (CPTax vs. CPTx, Michael et al., 1981), and the inter-stimulus interval is long ( $>1 \mathrm{sec}$, Chee et al., 1989). In paper/pencil lettercancellation tasks (e.g. D2) the test is selfpaced and conducted under time pressure. Subjects may make more errors of commission than omission (Aman, 1986; Brown and Wynne, 1992; not Gomez and Sanson, 1994). The opposite usually holds for the CPT, but this is also variable (review: Corkum and Siegel 1993). This confusion over the response pattern is not helpful where tests like the D2 are used as an aid in diagnostic procedures (cf. response patterns obtaining in the autistic spectrum, Oades et al., 1988).

Reports on signal-detection measures have used a range of CPT forms and are largely consistent on the issue of poorer detection performance in ADHD. But considering that $d^{\prime}$ is likely to vary with the task requirement few have reported on different tests in the same subjects (but see Nuechterlein, 1983, Halperin 1991). Indeed the different requirements of various CPTs have often given conflicting results on beta-criterion (lower, stable or higher in Nuechterlein, 1983; van der Meere and Sergeant, 1988; Seidel and Joschko, 1990, respectively). This lack of a consensus here is problematic considering the clear interaction between impulsivity, a feature of a group of ADHD children, and a cautious/liberal response-bias.

The third issue is that the CPT ax introduces a WM component to the task in addition to the concentration requirement of the CPT $x$ (Nuechterlein et al., 1994: here the subject must retain a WM of the letter 'a' to see if the next letter is an ' $x$ ', the target, or another nontarget letter). The possibility of an impaired WM in ADHD has not received widespread attention in CPT or other tests. But, such mechanisms could underlie impaired 
backwards and forwards, verbal digit-span and visuo-spatial tests (Milich and Loney, 1979; Karetkin and Asarnow, 1998). The literature has been reviewed and put in the context of frontal mechanisms of executive function (Denckla, 1996; Barkley, 1997).

The question of the involvement of WM function obtains significance in the debate on potential delayed development leading to impaired right frontal function in the aetiology of ADHD (Oades, 1998, Silberstein et al., 1998). Neuroimaging data implicate righthemisphere function in sustained attention (Coull, 1998). As measured with f-MRI the CPTax elicits increased activity in the left (WM-related) or right (difficulty-related) frontal cortex of young adults (Barch et al., 1997). In ADHD children MRI studies have noted smaller right frontal volumes (Castellanos et al., 1996b) and an association of right frontal measures with auditory CPT accuracy (Casey et al., 1997). (Unfortunately, the latter result was obscured by trends for an IQ association with the same measures.) Nonetheless, independently of how neuroimaging studies progress, a component in CPTax performance additional to that evident in the CPTx would be predicted. This component could reflect increasing task difficulty and/or WM.

The fourth issue studied in this report was a comparison of the influence of immediate feedback (reinforcement or distraction) on CPT ax performance. The role of immediate reinforcement on CPT measures was examined because some authors attribute poor performance to an insensitivity to gratification, delayed feedback, even an 'aversion to delays' (e.g. at the end of the task, laboni et al., 1995; Sonuga-Barke et al., 1998). Douglas (1988) listed 'a strong inclination to seek immediate reinforcement' as one of the 4 major characteristics of an ADHD child. The CPTax test was repeated with correct/incorrect responses accompanied by high/low tones, respectively. After such feedback, improved performance might be expected from ADHD children, even though a similar attempt at studying this variable did not prove successful at enhancing performance (Solanto, 1990).
The last part of this study was designed to explore if there were meaningful relationships of general indicators of monoaminergic activity (urinary metabolites) with performance that could guide an understanding of the bases of the neural systems underlying the anomalies and the appropriate prescription of corrective medication. Castellanos et al. (1994, 1996a) found baseline CSF HVA predicted a good clinical response of ADHD children to medication, and Halperin et al. (1997) found plasma MHPG levels were associated with IQ. Thus it is surprising that neither measures could be related to CPT performance. It is abundantly evident that both dopaminergic and noradrenergic medication can improve CPT performance (Levy, 1991; Chappell et al., 1998). 24h urinary samples have numerous advantages for providing non-invasive indications of transmitter activity independent of transient fluctuations, and estimates of the central origin of the metabolites vary from 15$30 \%$ (see extensive discussion Amin et al., 1992). Further Castellanos and colleagues reported trend relationships between urine and CSF collections of HVA and 5-HIAA that are not evident for plasma samples, and differential associations of urinary monoamine activity for associative learning, circulating peptides and behavior have already been reported in these children (Oades et al., 1996; Oades and Müller, 1997; Oades et al., 1998).

In summary, we report a comparison of four forms of measuring 'sustained attention' in ADHD and normal children, and a group with complex tics and comorbid attentiondeficit characteristics to provide an indication of the specificity of the results. We expected differences between the measures according to modality (D2 vs. CPT), to the intervening variable under test (concentration vs. WM), and the presence/absence of immediate feedback. The associations between performance and monoamine activity will be discussed in terms of what might be clinically appropriate to improve impairments, and the underlying mechanisms of action used by monoaminergic circuits in modulating the transmission of information used in cognitive tasks (e.g. Oades, 1985). 


\section{Methods}

\subsection{Subjects}

There were 14 children with ADHD, 11 with complex tic or Tourette syndrome (TS) and 14 healthy controls (CN: see Oades and Müller, 1997).The ADHD children were consecutive admissions with a primary DSM IIIR diagnosis from two independent clinicians of attention deficit- and hyperactivity-disorder (314.01 $[n=8])$ or undifferentiated attentional disorder (314.00 [ $n=6]$ : together termed AD). (Such admissions for extensive diagnostic procedures are not uncommon in Germany.) There were 12 boys and 2 girls free of medication (age-range 7.1-14.3y, mean 10.2 SD 2.2). Patients were only included if the dominant problem was one of attention deficit and their nonverbal IQ exceeded 70 (Raven's standard progressive matrices (SPM) mean 95, SD 13). Extensive interviews revealed some comorbidity that had not contributed to their referral. Five had mild, secondary mood disorders (313), five showed modest conduct problems (312), two had enuresis and/or encoporesis, and 3 had minor developmental coordination problems (315). The brief Conners ratings (1973), made by the parents and one of the ward staff (mean 1.7 SD 0.3), did not overlap with those of the healthy children (see below). Exclusion criteria also included other neurological or physical illness.

Patients who had been referred with Tourette's syndrome were sought for a comparison group that displays AD-like symptoms to determine the illness specificity of sustained attention performance in those with an ADHD diagnosis. Symptoms on the Conners scale were similar to the $A D$ group (mean 1.5, SD 0.3). A further feature that renders the comparison of interest is the differential response to the dopaminergic agent Ritalin that frequently exacerbates or moderates the symptoms of these groups, respectively. In practice 5 patients retained a primary diagnosis of Tourette's syndrome (307.23) while 6 were re-diagnosed with a chronic multiple tic syndrome (307.22). (These patients would probably receive a diagnosis of Tourette's syndrome with DSMIV where the requirement for simultaneous severe motor and vocal tics has been loosened.) Ten of these patients were male and one female (age-range 8.2-15.2 years, mean 11.9 SD 2.1). The mean IQ (99 SD 22) did not differ significantly from the other groups, and the tic severity/frequency averaged $2.1 / 1.7$ on a scale of $1-4$, from the Tourette-Syndrome global assessment scale, (Harcherik et al., 1984). Other comorbid illness was absent, and exclusion criteria were the same as for the $A D$ group as long as tics were the major problem diagnosed. Six patients were free of medication at testing, 2 received pimozide (1$1.5 \mathrm{mg} / \mathrm{d}$ ) and 3 tiapride $(200-400 \mathrm{mg} / \mathrm{d})$.

Healthy children (CN, 10 boys, 4 girls, agerange 8.2-14.2 years, mean 10.8 SD 1.6) were matched pair-wise with the $A D$ patients for age within 10 months and for Tanner ratings of sexual maturity within one level on the scale of 1-6. They were screened to exclude neurological or psychiatric illness requiring consultation (past or present), a history of organic disorder or other physical illness and medication using standard procedures for patients on admission, under direction of a clinician. Their mean IQ (111, SD 16) was higher than in the AD but not the TS patients (t 2.9, $p<0.01$; 1 1.5, $p=0.14$, respectively. Conners' ratings by the parents, though not directly comparable with those from the patients, indicated an absence of relevant problems in this group. The scores did not overlap (mean 0.66, SD 0.26) and all were below the criterion of 1.5 (laboni et al., 1995). Testing followed approval of the protocol by the clinic management, agreement of the therapists and nursing staff to the tests and the time point in each case and the cooperation, understanding and consent of the child and the legally responsible adult.

\subsection{Tasks}

The two main tasks were the D2cancellation and the continuous performance test (CPT). The cancellation task is a clinically routine pencil-and-paper test (Brickenkamp, 1962). There are 16 rows of the printed letters ' $d$ ' or ' $p$ ' with one or two marks over or under the letter. The subject is required to strike out the ' $d$ ' with two marks (D2), to perform the test as fast and as accurately as possible, and to move to the next line of letters when cued by the experimenter (every $20 \mathrm{sec}$ ). There are 
294 targets among 658 items. The task is a rule-based, self-paced test of 'sustained attention' lasting $4 \mathrm{~min} 40 \mathrm{sec}$ after one line of practice. The reaction time related variable consists of the number of items completed. The total number of trials and errors, and the percentage of omission and commission errors were scored (Table 1). Also shown is the improvement (error reduction) between the first and last 4 lines of the task.

The CPT (Rosvold et al., 1956) consisted of a temporal, pseudo-random sequence of letters presented on a PC programmed by $G$. Sjoberg and modified by D. Bunk. The subject was asked to press a button as soon as a target appeared, but to be as accurate as possible. In the simple form, the letter ' $x$ ' was the target (CPTx). In a more difficult form the target was the letter ' $x$ ' if preceded by the letter 'a' (CPTax). The simple CPTx is a rulebased, externally paced test of 'sustained attention', while the CPTax has a higher information load including an 'a' as a WM component (Nuechterlein et al., 1994). The CPTx lasted for $7 \mathrm{~min}$ and $34 \mathrm{sec}$ (115 targets and 285 non-targets). The CPT ax lasted for a similar period (96 targets and 304 nontargets). The f-CPT consisted of the CPTax for $3 \mathrm{~min}$ and $49 \mathrm{sec}$ (48 targets and 152 nontargets) with auditory feedback (a high tone followed a correct response, while a low tone followed errors of omission or commission). Letters were $1 \mathrm{~cm}$ high, viewed from $60 \mathrm{~cm}$ and presented for $130 \mathrm{~ms}$ at a rate of $1 / \mathrm{sec}$. Each was preceded by $1 \mathrm{~min}$ of practice.

\subsection{Biological Measures}

Urine was collected for $24 \mathrm{~h}$ between two days of neuropsychological tests while the subjects were on a strict low monoamine diet. Acidified samples were frozen at $-80^{\circ} \mathrm{C}$ for later blind analysis. Dopamine, noradrenaline and serotonin and their metabolites homovanillic acid (HVA), 3-methoxy-4hydroxyphenylglycol (MHPG) and 5hydroxyindoleacetic acid (5HIAA) were measured with ion exchange liquid chromatography and fluorescence detection. These measures were adjusted for volume and expressed as nanograms per gram creatinine per square meter body area to correct for general somatic metabolic rates and large variations of body size (Oades et al., 1994).

\subsection{Data treatment}

Signal detection measures of perceptual sensitivity ( $d^{\prime}$ ) and response criterion (beta) were analyzed following the natural logarithmic transformation of their derivation after Green and Swets (1966): [H = Hit rate + $0.5 /$ targets $+1 ; \mathrm{F}$ (false alarm rate) $=$ Commission rate $+0.5 /$ non-targets +1 ; $d$ prime $\left(d^{\prime}\right)=H(1-F) / F(1-H)$; beta $(ß)=$ nontargets - commits/ targets - omits.] The distribution of errors was not normally distributed $\left(\chi^{2}>10, p<0.01\right)$ and was analyzed with non-parametric methods, while the transformed signal detection measures and reaction times showed a normal distribution and were subjected to multivariate analysis covaried for IQ $\left(\chi^{2}<8, p>0.2\right)$.

Initially the dependent variables were calculated and analyzed separately for each task. The hypothesis was tested that the intervening variable ('sustained attention' or concentration vs. task difficulty or working memory), as measured by signal-detection variables, was similar between the three tests by standard and stepwise linear regression. The same approach was used to determine the influence of reinforcement (CPTax vs. fCPT, each $3.8 \mathrm{~min}$ ). Spearman correlation coefficients are reported merely as indicators of possible relationships between signal detection measures on the CPT ax and measures of monoamine activity: the relative contribution of the metabolites was assessed with partial correlations.

\section{Results}

\subsection{Separate consideration of the D2-} cancellation-, CPTX and CPTax tasks

Groups did not differ in the D2-task on the number of items completed, or accuracy. The tendency for $A D$ patients to make more commission errors in the last four lines of the test was not significant (Table 1). In an analysis of signal detection measures $d^{\prime}$ was merely $9-15 \%$ better in the $C N$ vs. the $A D$ and TS groups respectively $(F[4,56]=0.3, p<$ 0.85, Fig. 1). 


\begin{tabular}{|c|c|c|c|c|c|c|}
\hline $\begin{array}{l}\text { Measure: } \\
\text { (Mean, S.D.) } \\
\text { Group: } \\
\end{array}$ & $\begin{array}{l}\% \text { of } \\
658 \text { items }\end{array}$ & $\begin{array}{l}\text { Hit } \\
\text { Rate }\end{array}$ & $\begin{array}{l}\text { Sum } \\
\text { Errors }\end{array}$ & $\begin{array}{l}\% \\
\text { Omit }\end{array}$ & $\begin{array}{l}\% \\
\text { Commit }\end{array}$ & $\begin{array}{l}\text { Error difference } \\
1 \text { st to last } 4 \text { lines }\end{array}$ \\
\hline $\mathbf{C N}_{(n=12)}$ & $\begin{array}{r}42.5 \\
7.4\end{array}$ & $\begin{array}{c}89.9 \\
9.0\end{array}$ & $\begin{array}{l}18.3 \\
17.3\end{array}$ & $\begin{array}{l}9.8 \\
9.0\end{array}$ & $\begin{array}{l}4.4 \\
6.1\end{array}$ & $\begin{aligned}- & 1.00 \\
& 0.84\end{aligned}$ \\
\hline $\begin{array}{l}\text { TS } \\
\quad(n=10)\end{array}$ & $\begin{array}{l}47.6 \\
20.4\end{array}$ & $\begin{array}{r}88.7 \\
8.6\end{array}$ & $\begin{array}{l}22.5 \\
16.1\end{array}$ & $\begin{array}{r}11.0 \\
8.7\end{array}$ & $\begin{array}{l}4.8 \\
4.6\end{array}$ & $\begin{array}{r}-3.00 \\
3.64\end{array}$ \\
\hline $\begin{array}{l}\text { AD } \\
\quad(n=12)\end{array}$ & $\begin{array}{c}41.8 \\
12.2 \\
\end{array}$ & $\begin{array}{r}88.5 \\
10.9 \\
\end{array}$ & $\begin{array}{r}22.1 \\
20.0 \\
\end{array}$ & $\begin{array}{r}11.1 \\
11.0 \\
\end{array}$ & $\begin{array}{r}7.0^{1} \\
6.3 \\
\end{array}$ & $\begin{array}{r}0.00^{2} \\
2.65 \\
\end{array}$ \\
\hline
\end{tabular}

There were no significant differences between groups. Mann Whitney U-tests $v s . \mathrm{CN} 1 . \mathrm{U}=52, \mathrm{z}=-$ $1.1, \mathrm{p}=0.26: 2$. $\mathrm{U}=51, \mathrm{z}=-0.9, \mathrm{p}=0.36$.

Table 2

\section{Performance on the CPTx and CPTax Tasks}

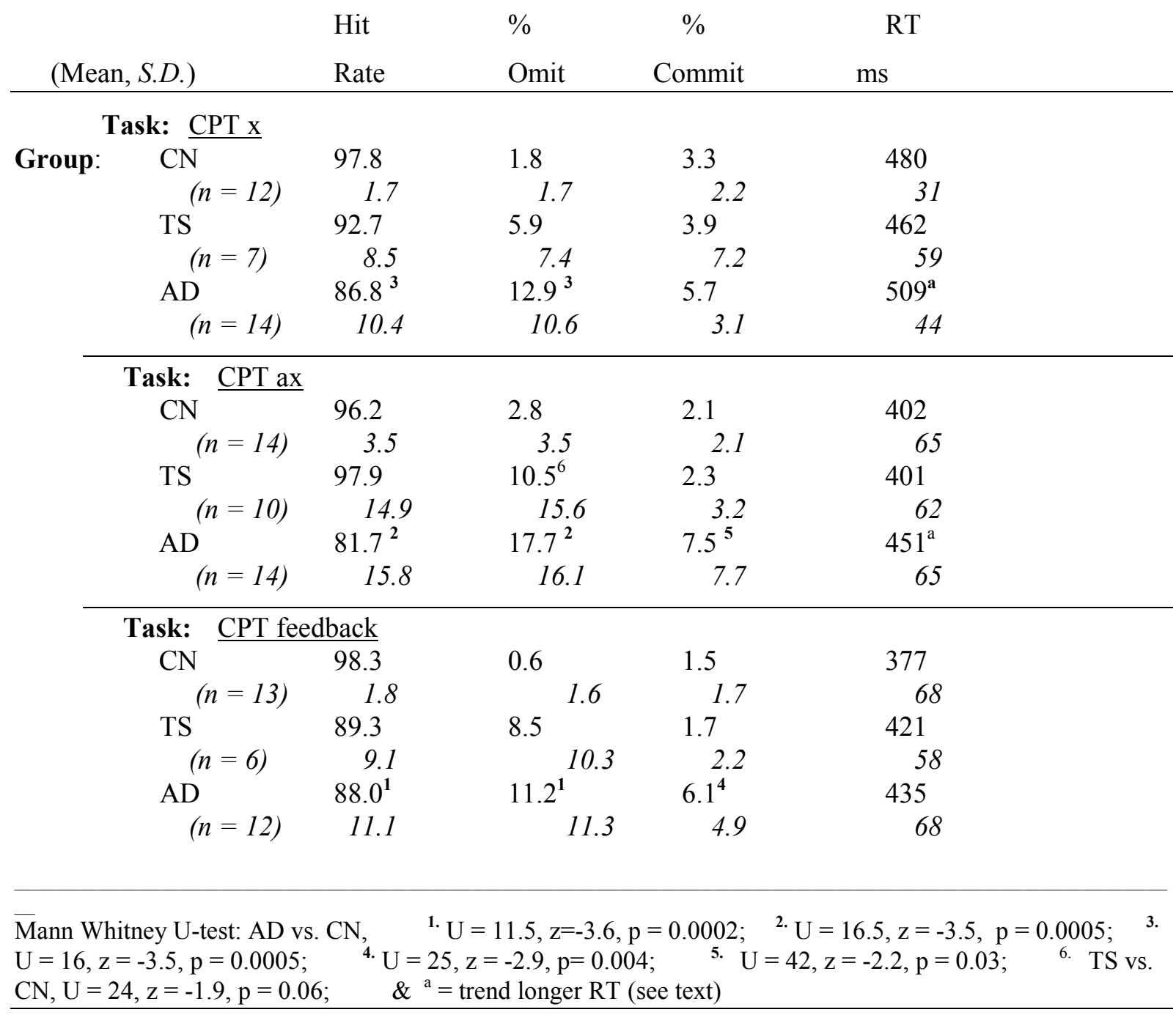

In contrast, a MANOVA covarying for IQ showed clear group differences on the CPTX for $d^{\prime}$ and beta $(F[4,56]=10.6, p<0.00001)$. In $A D$ children $d^{\prime}$ was $30 \%$ lower than for controls, and for TS children beta was twice as conservative as for the other groups (Fig. 1).
These differences were based on a lower hitrate and more errors of omission (not of commission) in the $A D$ group (Table 2). The $A D$ group also tended to show longer reaction times $(F[2,29]=2.9, p=0.072)$. 
A similar MANCOVA for CPTax performance confirmed the lower $d^{\prime}$ for $A D$ children (by $37 \%$ vs. CN), but that the TS response bias remained twice as high as in the other groups $(F[4,66]=9.5, p<0.00001)$. These differences were based on a poorer hitrate for $A D$ children associated with more errors of omission and commission than in the other groups: this contrasted with the tendency for only omission errors to be elevated in the TS group (Table 2). Again the $A D$ reaction times tended to be slower $(F[2$, $33]=3.2, p=0.053$ ).

With feedback (f-CPT) a MANCOVA confirmed the low $d^{\prime}$ in $A D$ children $(F[4,52]$ $=9.4, p<0.00001$ ). In addition to the large response-bias in the TS group, a separate analysis for $d^{\prime}$ showed that the detection thresholds for TS children were lower than in the controls $(F[2,14]=9.5, p<0.0025$ : Fig. 1$)$. These data reflected many more errors of omission and commission in the patients (Table 2). Repeated measures testing suggested an effect of feedback on the two signal detection measures $(F[6,46]=3.8, p<$ 0.004 ), however it could only be shown that there was a trend for a combined improvement of $d^{\prime}$ across groups (Scheffe, $p=$ 0.056: Fig. 1). The effect was based on trends for the $A D$ group to decrease omissions (alone) and the controls to decrease errors of omission and commission (Wilcoxon, $z=1.7$ 1.8, $p=0.07-0.09$ : Table 2).

Summary: 1) Sensitivity ( $\left.d^{\prime}\right)$ was poorer in $A D$ children in all CPT tasks, but not in the cancellation-task. 2) Omission and commission errors were more evident in the CPTax than CPTx task for AD children, although TS children's errors were largely of omission. 3) Response-bias (beta) became progressively more conservative in TS children in the CPT tasks (vs. CN and AD groups). 4) Feedback resulted in decreases of omission errors in $A D$ and $C N$ groups, but an increase for $d^{\prime}$ was more marked in the $\mathrm{CN}$ group.

Figure 1: Comparisons of perceptual sensitivity (ln d-prime: left) and response criterion (ln beta: right) for healthy children (CN), and those with ADHD (AD) or complex tics and Tourette syndrome (TS) on 4 tests of 'sustained attention' (D2-cancellation, continuous performance CPT x, CPTax and CPTax with feedback, f-CPT).

Signal Detection Indices (d-prime [left] and beta-criterion [right]) across 4 tests of 'sustained attention' for 3 groups of children (CN, AD, TS).

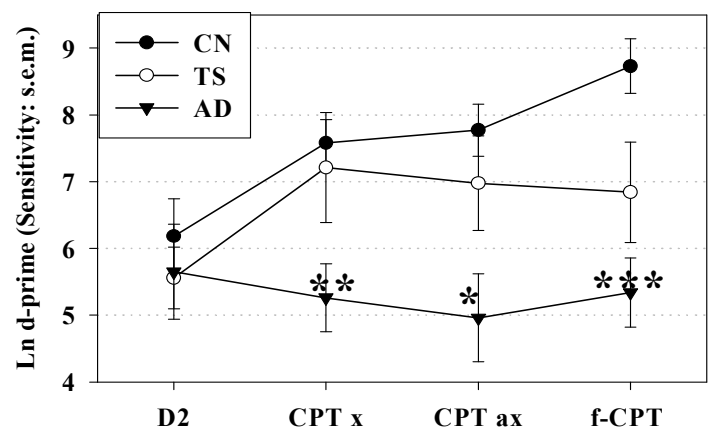

Tasks: Cancel \& Continuous Performance $(f=$ feedback) Scheffe: ${ }^{*}=\mathrm{p}<0.04(v s \mathrm{CN}) ; * *=\mathrm{p}<0.01(v s$ TS \& CN), $* * *=\mathrm{p}<0.001(v s \mathrm{CN})$

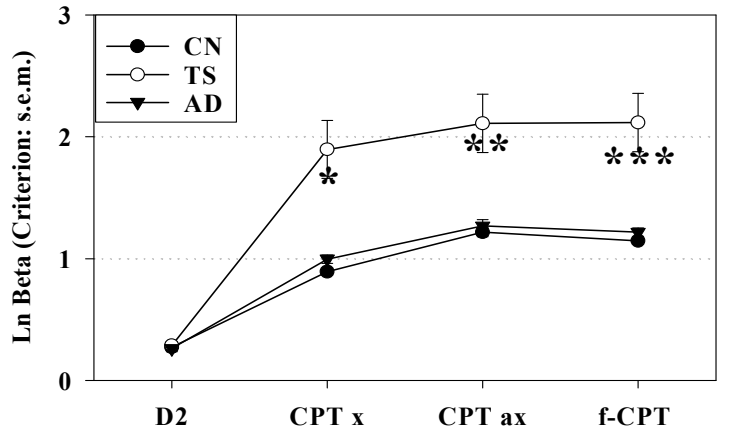

Tasks: Cancel \& Continuous Performance $(\mathrm{f}=$ feedback) Scheffe: $\mathrm{p}<0.001 ; * \mathrm{TS}$ vs $\mathrm{CN} \& \mathrm{AD}, * * \mathrm{TS}$ vs AD \& CN, *** TS vs AD \& CN 


\subsection{Relationship of signal detection measures} between the 'sustained attention' tasks

To assess the commonalities between the tests of sustained attention in terms of signal detection measures, standard and stepwise linear regressions were performed for $\mathrm{d}^{\prime}$ and beta, separately. The first question was to what extent CPT measures explained those recorded in the D2 task. The model was not significant for beta-criterion with perhaps $5 \%$ of the variance explained (beta-weight 0.23 ). But, the model was significant for d' (betaweight 0.41; $F[1,29]=5.96, p<0.02)$. Nonetheless, the CPTx measure explained only $17 \%$ of the variance that, in a step-wise analysis was increased by only $5 \%$ with the other two CPT tests (not significant).

The second question asked to what extent CPT ax measures reflected merely features of concentration like CPT $\mathrm{x}$ or there was a difference, likely reflecting the increased WM aspect of the task. Models were significant for both $d^{\prime}$ and beta values (beta-weights 0.66 and 0.86 , respectively: $F[1,32]=25 / 94, p<$ $0.00001)$. In turn these values explained $44 \%$ and $75 \%$ of the variance, suggesting that features like concentration were important to both tasks.

But the answer to the third question on the extent to which measures on the CPT ax and $\mathrm{f}$-CPT overlapped, pointed to a significant contribution of the putative working memory component. Here $d^{\prime}$ and beta on f-CPT explained $61 \%$ and $93 \%$ of the variance in the CPT ax (beta-weights 0.78 and 0.96: $F[1,30]=$ $46 / 300, \mathrm{p} \ll 0.00001)$. The step-wise analysis confirmed that while f-CPT explained nearly two thirds of the CPTax variance, where the contribution of the CPTx was not significant.

Summary: The commonalities between cancellation and CPT tests in terms of signal detection measures were very small compared to those seen between CPTx and CPTax tasks. The difference in variance explained in comparing CPTx and CPTax vs. CPTax and $\mathrm{f}$-CPT implied that there was an intervening variable in the CPTax condition (e.g., WM or task difficulty) in addition to that in the CPTx (e.g., 'sustained attention').

\subsection{Monoamine Activity}

a) Group differences: Monoamine and metabolite levels for these subjects groups have been published (Oades and Müller, 1997). Noradrenaline and MHPG levels did not differ between groups. Dopamine levels were lower and HVA levels higher in the TS children. Serotonin levels were lower in the TS and 5HIAA levels were higher in the AD children. In terms of utilization, dopamine activity was higher in the TS children and noradrenaline activity lower in both patient groups vs. the controls. The HVA/5-HIAA ratio was significantly depressed in the $A D$ group with respect to $\mathrm{CN}$ and TS children.

b) Associations with signal detection measures: To provide a working hypothesis for future study correlations were sought between $d^{\prime}$ and beta measures and indices of monoamine metabolism (the metabolites of dopa-mine, HVA, of noradrenaline, MHPG and of serotonin, 5-HIAA) and their relative activity expressed by the ratios HVA/MHPG and HVA/5-HIAA. To protect $\alpha$ we restricted the number of correlations sought for the 8 amine measures to the CPTax that has been shown (above) to reflect features that may be related to concentration and to WM. Thus, an $\alpha$ of 0.05 is considered as a trend, and 0.01 to represent potential significance.

The only correlation evident for controls was a negative association for d' with HVA $(n=14,-0.72, p=0.004)$. For the $A D$ group there was also a negative association for $d^{\prime}$, but with 5-HIAA ( $n=13,-0.65, p=0.01$; Fig. 2). But there were also intriguing relationships with the other amines in the $A D$ group: HVA/5-HIAA was positively related to d' but negatively to beta $(+/-0.5, p=0.01)$. Further HVA/MHPG tended to be negatively related to $d^{\prime}$, the opposite direction to the relationship with the serotonin metabolite $(-0.4, p=0.05)$. There were no associations for the TS group reaching the present statistical criteria, but for comparative purposes the negative relationship of $d^{\prime}$ to HVA is illustrated in fig. 2.

In order to obtain an indication of the relative importance of the metabolites together they were entered into a regression and partial correlations calculated $(F[3,10]=$ 3.7, $p=0.05)$ : the importance of HVA for 
controls was confirmed, but the trend pointed surprisingly to a larger role for MHPG in the AD group than for 5 -HIAA $(+0.53 p=0.07 v s$. $0.43, p=0.16)$.

Summary: Considering the CPTax task as representative of 'sustained attention' performance, there was a negative relation of $d$ ' with HVA in healthy children, but a negative relation with 5 -HIAA for AD children. This may obtain functional significance in the light of apparent positive and negative associations for the ratio of serotonin to dopamine and serotonin to noradrenaline activity, respectively. For comparison, TS children showed modest non-significant negative associations. Beta had few associations with monoaminergic metabolites.

\section{Figure 2:}

Comparisons of the correlations of monoamine metabolites with ln d-prime in the CPTax task. [Left] Homovanillic acid (HVA) in controls decreases as d-prime increases (remains significant after removal of extreme HVA value: $r=-0.62, p=0.02$ ). [Middle] 5-hydroxy-indoleacetic acid (5-HIAA) in $\mathrm{AD}$ children decreases as d-prime increases (remains significant after removal of extreme 5HIAA value: $r=-0.73, p=0.007$ ). [Right] A trend similar to $\mathrm{CN}$ is evident for TS children; (the trend remains after removal of extreme HVA value: $r=-0.52, p=0.1$ ).

\section{Signal detection indices (ln d-prime) vs. monoamine metabolites (24h samples) in CN, AD and TS groups}
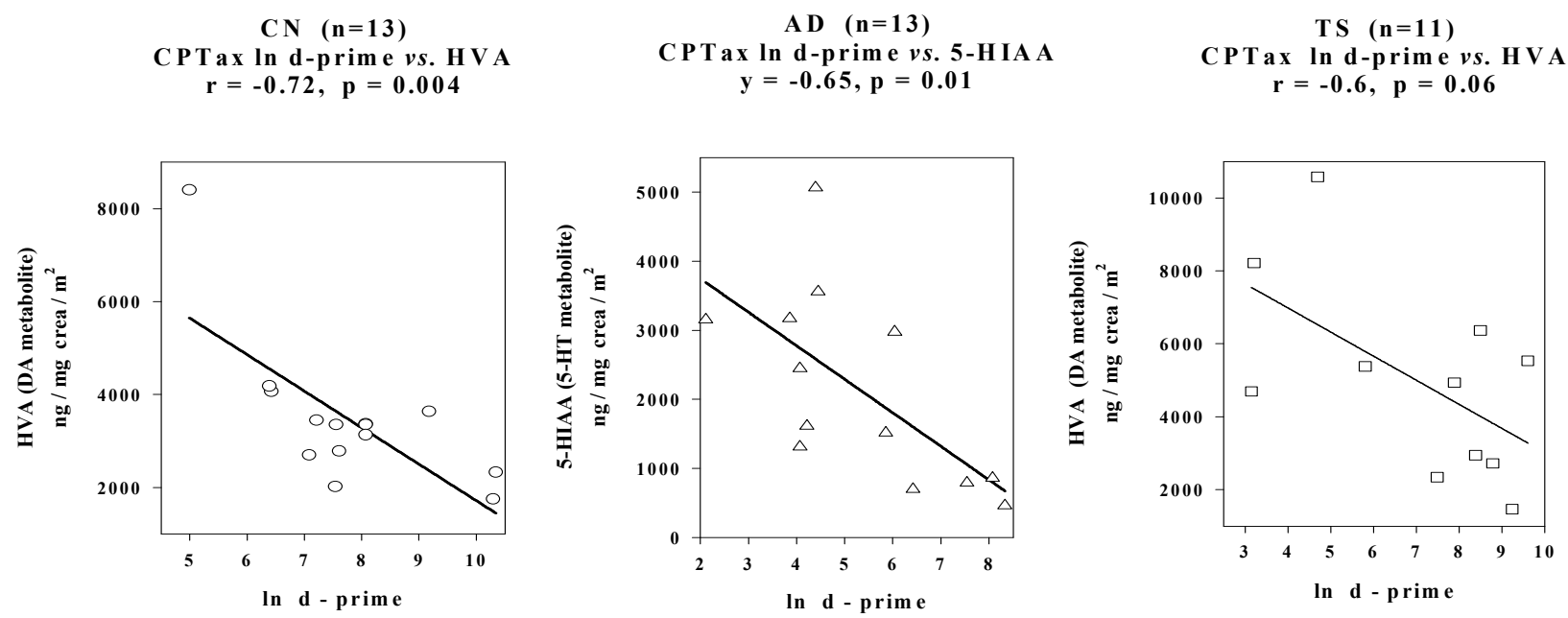

\section{Discussion}

The first issue concerns the usefulness of the D2 paper/pencil task for differentiating the attention-related performance of patients with $A D$ symptoms. Minor performance differences were not significant after taking
performance-IQ into consideration. Thus, this result suggests that the $\mathrm{D} 2$-test is insensitive to the performance of AD-like patients. This is in line with some previous criticism of cancellation-tests (Gomez and Sanson, 1994; Matier et al., 1994), but the data do not rule 
out that such tests may be sensitive to subjects showing reading and learning-related deficits (Halperin, 1991).

Performance on the CPT contrasts with that on the D2-task. On the simple CPTx AD children showed a reduced level of perceptual sensitivity or attentional capacity ( $d^{\prime}$ ) by comparison with healthy or TS children. On the other hand TS children showed a more conservative response style (beta) - a tendency to under- rather than over-respond compared with the controls. On the more difficult CPTax the $d^{\prime}$ in AD children stayed equally poor, while beta-criteria remained similar to controls, and less conservative than in the TS children.

The regression analyses confirmed the expectation that there was a significant but small common element to the D2 and CPT $x$ task, and that the D2-task proved insensitive to group differences. Both CPT tasks were better at showing up differences in $d^{\prime}$ and response-bias. This analysis also showed there was a large proportion of variance shared between the CPT $x$ and CPT ax. However, as would be expected, the variance shared between the CPT ax and its repeat as f-CPT (with feedback) was much larger still. This is interpreted to imply that while one type of ability is held in common by the CPT $x$ and CPT ax (e.g. to 'sustain attention'), there is an additional component in the CPT ax that can be explained by increased difficulty, or, integral to the CPT ax design, the WM component.

The present data provide indirect empirical evidence for Nuechterlein's interpretation (1994) of CPT ax performance in terms of WM. This has implications for understanding the bases for ADHD. Such WM abilities in mature brains, especially as task-difficulty increases, depend on frontal function on the right side (Coull et al., 1997; Barch et al., 1997). On the basis of neuroimaging and electrical event-related recording Oades (1998) proposed that precisely this region did not function so well in ADHD children by comparison with normal children. This has now been elegantly demonstrated with psychophysiological measures of activation in a CPT ax vs. a CPT $x$ task (Silberstein et al., 1998).

The effect of feedback requires some comment. The finding here that all children benefited from feedback may be said to be well known (Firestone and Douglas, 1975; O'Dougherty et al., 1984). However, in related paradigms, ADHD children have been found to be impervious to such information (Sergeant and van der Meere, 1988; Solanto, 1990). Thus, it is of interest that all children made fewer errors in the f-CPT, but only the controls subtly but significantly improved their sensitivity. In view of increasing interest in what features of the childhood $A D$ syndrome survive in the adult residual form, an important consideration is that the strategy for sorting sensory information may change with increasing maturity. In this laboratory we have found that for adolescents over 14 years, healthy and patient groups, such feedback tends to interfere with CPT performance (Rust and Oades, 2000). Thus the immature nervous system is especially sensitive to input influencing sensitivity ( $d^{\prime}$ ).

In summary, the basic performance differences between $A D$ and control children were consistent with a broad consensus of the literature. Reaction times were somewhat slower, $d$ ' was poorer, and more so on the more difficult task (Sykes et al., 1971; Leung and Connolly, 1995; Van Leeuwen et al., 1998). A lack of difference of beta-criterion in $A D$ children is consistent with some reports (Corkum and Siegel, 1993) but not others describing lower values (Hooks et al., 1994; van Leeuwen et al., 1998). A more liberal criterion is more likely if the task is difficult and the targets rare (van Leeuwen et al., 1998), or the children are more emotional and show less fear inhibition (Nuechterlein 1983). But here a more conservative criterion was apparent in children with Tourette/Tic diagnoses.

Urinary monoamines and their metabolites were studied as indicators of overall transmitter activity in the body and brain over time, independent of phasic events or circadian changes. The disadvantages are wellknown, in view of peripheral noradrenaline and serotonin systems only a small proportion 
of excreted monoamines derives from the CNS, and HVA in part derives from noradrenaline metabolism. The advantages are also considerable, considering that measures purportedly tend to reflect CSF, and that the taking of CSF from children can rarely be justified (see Amin et al., 1992). Further, plasma levels repeatedly produce no correlations with CPT performance or symptoms (Halperin et al., 1997). What then were the indications for an association with CPT performance, and for helpful medication?

On the CPT ax improved $d^{\prime}$ related to decreased HVA in healthy children. This is consistent with the interpretative schema advanced by Oades (1985). He suggested that increasing DA activity in an area receiving input and delivering output about an ongoing response increased the likelihood of a switch between the input and alternative outputs. Thus low DA activity would permit learned CPT performance to be maintained. The principle was shown by Oades (1997), where subjects with lower DA activity learned a single discrimination faster, but those with higher DA activity learned reversals of the discrimination faster. In contrast to controls, HVA was important for the AD group only in the context of the activity of the other amines.

In $A D$ patients 5-HIAA levels were negatively related to performance. This is consistent with the hypothesis that serotonin activity mediates a form of volume control on signal processing (Oades, 1995). In this scheme high activity permits ongoing processing, whereas under low activity other features may compete for processing and influence response. But for $A D$ patients trend relationships with other amines were noted. Poor d' was related to decreased HVA/5-HIAA ratios. (This ratio is markedly depressed in the AD group [Oades and Müller, 1997].) But as a counterpoint, HVA/MHPG ratios tended to be negatively related to $d^{\prime}$. Perhaps the most interesting feature here is the apparent possibility that dopamine activity may be relatively high with respect to noradrenergic, but relatively low with respect to serotonergic activity. If replicated with more subjects this would have implications for pharmacotherapy.

These findings can be considered as consistent with the limited literature on monoamine activity in these groups. For example, high blood serotonin levels were reported to be associated with increased commission errors (Cook et al., 1995), increased serotonergic activity in CSF samples correlated with hyperactivity and $A D$ symptoms (Castellanos et al., 1996a) and low urinary HVA/5-HIAA ratios recorded in the present $A D$ group were related to poor conditioned-blocking measures of selective attention (Oades and Müller, 1997). While the helpfulness of psychostimulants on noradrenergic (Chappell et al., 1998) and dopaminergic function is established (Pelham et al., 1990), it may be worth examining agents that suppress serotonergic activity for their use in treating AD-like symptoms in TS and ADHD patients.

There are clear limits to the results: the subjects sampled were few, the monoamine measures were indirect indicators of neural activity, and the 'attentional' tests were a limited selection of those available. Further, the behavioral problems secondary to the primary diagnosis of ADHD were not the typical ones of developmental learning or oppositional problems. Despite this the signaldetection measures were remarkably distinct with relatively small deviances. The nature of these measures did vary with one frequent problem, namely tics. The interest in the biological data will lie in the ability to replicate them in more practical 'on-the-spot' collections rather than the more difficult $24 \mathrm{~h}$ samples used here.

\section{Acknowledgments}

The author is grateful to Gary Sjoberg (Flinders University) and Dr. Detlef Bunk (University of Essen) for programming assistance. Thanks are also due to Dr. Renate Schepker for confirming diagnoses, Dr. Alexandra Balcar for her advice and Professor C. Eggers and Dr. M. Möllering for their support. Monoamine analyses were performed by Dr. Bussemass at the $\mathrm{Dr}$ Eberhard laboratory, Dortmund. 


\section{References}

Aman, M.G., 1986. Incidental learning, distraction and sustained attention in hyperactive and control subjects. Journal of abnormal Child Psychology 14, 441-455.

Amin, F., Davidson, M., Davis, K.L., 1992. Homovanillic acid measurement in clinical research: a review of the methodology. Schizophrenia Bulletin 18, 123-148.

Barch, D.M., Braver, T.S., Nystrom, L.E., Forman, S.D., Noll, D.C., Cohen, J.D., 1997. Dissociating working memory from task difficulty in human prefrontal cortex. Neuropsychology 35, 1373-1380.

Barkley, R.A., Grodzinsky, G.M., DuPaul, G.J., 1992. Frontal lobe dysfunctions in attention deficit disorder with and without hyperactivity: a review and a research report. Journal of abnormal Child Psychology 20, 63-188.

Brickenkamp R 1962. Aufmerksamkeitsbelastungstest. Hofgrefe, Göttingen

Brown, R.T., Wynne, M.E., 1992. Correlates of teacher ratings, sustained attention and impulsivity in hyperactive and normal boys. Journal of Clinical Child Psychology 1, 262267.

Campbell, J.W., D'Amato, R.C., Raggio, D.J., Stephens, K.D., 1991. Construct validity of the computerized continuous performance test with measures of intelligence, achievement and behavior. Journal of School Psychology 29, 127-134.

Casey, B.J., Castellanos, F.X., Giedd, J.N., Marsh, W.L., Hamburger, S.D., Schubert, A.B., Vauss, Y.C., Vatuzis, A.C., Dickstein, D.P., Sarfatti, S.E., Rapoport, J.L., 1997. Implication of right fronto-striatal circuitry in response inhibition and attentiondeficit/hyperactivity disorder. Journal of the American Academy Child and Adolescent Psychiatry 36, 374-383

Castellanos, F.X., Elia, J., Kruesi, M.J.P., Gulotta, C.S., Mefford, I.N., Potter, W.Z., Ritchie G.F., Rapoport, J.L., 1994. Cerebrospinal fluid monoamine metabolites in boys with attention-deficit hyperactivity disorder. Psychiatry Research 52, 305-315.

Castellanos, F.X., Elia, J., Kruesi, M.J.P., Marsh, W.L., Gulotta, C.S., Potter, W.Z., Ritchie G.F., Hamburger, S.D., Rapoport, J.L., 1996a. Cerebrospinal fluid homovanillic acid predicts behavioral response to stimulants in 45 boys with attention deficit/hyperactivity disorder. Neuropsychopharmacology 14, 125-137.

Castellanos, F.X., Giedd, J.N., Marsh, W.L., Hamburger, S.D., Vaituzis, A.C., Dickstein, D.P., Sarfatti, S.E., Wauss, Y.C., Snell, J.W., Kange, N., Kaysen, D., Krain, A.L., Ritchie, G.F., Rajapakse, J.C., Rapoport, J.L., 1996b. Quantitative brain magnetic resonance imaging in attention-deficit hyperactivity disorder. Archives of General Psychiatry 53, 607-616

Chappell, P.B., Riddle, M.A., Scahill, L., Lynch, K., Schultz, R., Arnsten, A.F.T., Leckman, J.F., Cohen, D.L., 1998. Guanfacine treatment of comorbid attention deficit disorder and Tourette's syndrome: preliminary clinical experience. Journal of the American Academy of Child and Adolescent Psychiatry 34, 1140-1146.

Chee, P., Logan G.D., Schachar, R.J., Lindsay, P., Wachsmuth, R., 1989. Effects of event rate and display time on sustained attention in hyperactive, normal and control children. Journal of Abnormal Child Psychology 17, 371-391.

Conners, C.K. 1973. Rating scales for use in drug studies with children. Psychopharmacology Bulletin 9, 24-29

Corkum, P.V., Siegel, L.S., 1993. Is the continuous performance task a valuable research tool for use with attention-deficithyperactivity disorder? Journal of Child Psychology and Psychiatry 34, 1217-1239.

Cook, E.H., Stein, M.A., Ellison, T., Unis, A.S., Leventhal, B.L., 1995. Attention deficit hyperactivity disorder and whole blood serotonin levels: effects of comorbidity. Psychiatry Research 57, 13-20.

Coull, J.T., 1998. Neural correlates of attention and arousal: insights from electrophysiology, functional neural imaging and psychopharmacology. Progress in Neurobiology 55, 343-361.

Coull, J.T., Frith, C.D., Frackowiak, R.S.J., Grasby, P.M. , 1997. A fronto-parietal network for rapid visual information processing: a PET study of sustained attention and working memory. Neuropsychologia 34, 1085-1095. 
Denckla, M.B. 1996. Research on executive function in a neuro-developmental context: application of clinical measures. Developmental Neuropsychology 12, 5-15.

Douglas, V.I., 1988. Cognitive deficits in children with attention deficit disorder with hyperactivity. In: Bloomingdale, L.M. Sergeant, J. (Eds.), Attention deficit disorder: criteria, cognition, intervention. Pergamon Press, London, pp. 65-82.

Dykman, R.A., Ackerman, P.T., Oglesby, D.M., 1979. Selective and sustained attention in hyperactive, learning disabled and normal boys Journal of Nervous and Mental Disease 167, 288-297.

Firestone, P., Douglas, V.I., 1975. The effects of reward and punishment on reaction times and autonomic activity in hyperactive and normal children. Journal of Abnormal Child Psychology 3, 201-216.

Gomez. R., Sanson, A., 1994. Effects of experimenter and mother presence on the attentional performance and activity of hyperactive boys. Journal of Abnormal Child Psychology 22, 517-529.

Green, D.M., Swets, J.A., 1966. Signal detection theory and psychophysics. J. Wiley, London.

Halperin, J.M., 1991. The clinical assessment of attention. International Journal of Neuroscience 58, 171-182.

Halperin, J.M., Newcorn, J.H., Koda, V.H., Pick, L., McKay, K.E., Knott, P., 1997. Noradrenergic mechanisms in ADHD children with and without reading disabilities: a replication and extension. Journal of the American Academy of Child and Adolescent Psychiatry 36, 1688-1697

Harcherik, D.F., Leckman, J.F., Detlor, J., Cohen, D.J. 1984. A new instrument for clinical studies of Tourette's syndrome. Journal of the American Academy of Child and Adolescent Psychiatry 23, 153-160.

Hooks, K., Milich, R., Lorch, E.P., 1994. Sustained and selective attention in boys with attention deficit hyperactivity disorder. Journal of Clinical Child Psychology 23, 69-77.

Horn, W.F., Wagner, A.E., lalongo, N., 1989. Sex differences in school-aged children with pervasive attention-deficit hyperactivity disorder. Journal of Abnormal Child Psychology, 17, 109-125.

Iaboni, F., Douglas, V.I., Maker, A.G., 1995. Effects of reward and response costs on inhibition in ADHD children. Journal of Abnormal Psychology 104, 232-240.

Karetekin, C., Asarnow, R.F., (1998). Working memory in childhood-onset schizophrenia and attention-deficit/ hyperactivity disorder. Psychiatry Research 80, 165-176.

Klee, S.H., Garfinkel, B.D., 1983. The computerized continuous performance test: a new measure of inattention. Journal of Abnormal Child Psychology 11, 487-496.

Klorman, R., Salman, L.F., Pas, H.L., Borgstedt, A.D., Dainer, K.B., 1979. Effects of methylphenidate on hyperactive children's responses during passive and active attention. Psychophysiology 16, 23-29.

Leung, P.W.L., Connolly, K.J., 1995. Attentional difficulties in hyperactive and conductdisordered children: a processing deficit. Journal of Child Psychology Psychiatry 35, 1229-1245.

Levy, F. 1991. The dopamine theory of attention-deficit hyperactivity disorder (ADHD). Australian and New Zealand Journal of Psychiatry 25, 277-283.

Luria, A.R., 1959. Experimental study of the higher nervous activity of the abnormal child. Journal of Mental Deficiency Research 3, 1-22

Matier, K., Wolf, L.E., Halperin, J.M. 1994. The psychometric properties and clinical utility of a cancellation test in children. Developmental Neuropsychology 10, 165177

Michael, R.L., Klorman, R., Salzman, L.F., Borgstedt, A.D., Dainer, K.B., 1981. Normalizing effects of methylphenidate on hyperactive children's vigilance and evoked potentials. Psychophysiology 18, 665-677.

Milich, R., Loney, J., 1979. The factor composition of the WISC for hyperkinetic/MBD males. Journal of Learning Disabilities 12, 67.

Nuechterlein, K. H., 1983. Signal detection in vigilance tasks and behavioral attributes among offspring of schizophrenic mothers and among hyperactive children. Journal of Abnormal Psychology 92, 4-28. 
Nuechterlein, K.H., Dawson, M.E., Green, M.F., 1994. Information-processing abnorm-alities as neuropsychological indicators for schizophrenia. Acta Psychiatrica Scandinavica 90 (suppl. 384), 71-79

Oades, R.D., 1985. The role of noradrenaline in tuning and dopamine in switching between signals in the CNS. Neuroscience and Biobehavioral Reviews 9, 261-283.

Oades, R.D., 1995. Connections between studies if the neurobiology of attention, psychotic processes and event-related potentials. Electroencephalography and clinical Neuro-physiology, supplement 44, 428-438

Oades, R.D., 1997. Stimulus dimension shifts in patients with schizophrenia, with and without paranoid hallucinatory symptoms, or obsessive compulsive disorder: strategies, blocking and monoamine status. Behavioral Brain Research 88, 115131.

Oades, R.D., 1998. Frontal, temporal and lateralized brain function in children with attention-deficit hyperactivity disorder: a psychophysiological and neuropsychological viewpoint. Behavioral Brain Research 91, 83-95.

Oades, R.D., Müller, B., 1997. The development of conditioned blocking and monoamine metabolism in children with attention-deficit-hyperactivity disorder or complex tics and healthy controls: an exploratory analysis. Behavioral Brain Research 88, 95-102.

Oades, R.D., Daniels, R., Rascher, W., 1998. Plasma neuropeptide $Y$ levels, monoamine metabolism, electrolyte excretion, and drinking behaviour in children with attention-deficit hyperactivity disorder (ADHD). Psychiatry Research 80, 177-186

Oades, R.D., Röpcke, B., Eggers, C., 1994. Monoamine activity reflected in urine of young patients with obsessive-compulsive disorder, psychosis with and without reality distortion and healthy subjects: an explorative analysis. Journal of neural Transmission 96, 143-159

Oades, R.D., Röpcke, B., Schepker, R., 1996. A test of conditioned blocking and its development in childhood and adolescence: relationship to personality \& monoamine metabolism. Developmental Neuropsychology 12, 207-230.

Oades, R.D., Walker, M.K., Geffen, L.B., Stern, L.M., 1988. Event-related potentials in autistic and healthy children on an auditory choice reaction time task. International Journal of Psychophysiology 6, 25-37.

O'Dougherty, M., Nuechterlein, K.H., Drew, B., 1984. Hyperactive and hypoxic children: signal detection, sustained attention and behavior. Journal of Abnormal Psychology 93, 178-191.

Pelham, W.E., Greenslade, K.E., VoddeHamilton, M., Murphy, D.A., Greenstein, J.J., Gnagy E.M., Dahl, R.E., 1990. Relative efficacy of long-acting stimulants on ADHD children: a comparison of methylphenidate, Ritalin SR-20, Dexedrine Spansule and Pemoline. Pediatrics 86, 226237.

Rosvold, H.E., Mirsky, A.F., Sarason, J., Bransome, E.D., Beck, L.H., 1956. A continuous performance test of brain damage. Journal of Consulting Psychology 20, 343-350.

Rust, S., Oades, R.D., 2000. Signal detection measures during sustained attention distinguish schizophrenia with and without delusions and hallucinations. Schizophrenia Research 42,

Seidel, W.T., Joschko, M., 1990. Evidence of difficulties in sustained attention in children with ADDH. Journal of Abnormal Child Psychology 18, 217-229.

Sergeant, J.A., van der Meere, J., 1988. What happens when the hyperactive child commits an error? Psychiatry Research 24, 157-164.

Silberstein, R.B., Farrow, M., Levy, F., Pipingas, A., Hay, D.A., Jarman, F.C. 1998. Functional brain electrical activity mapping in boys with attention-deficit/hyperactivity disorder. Archives of General Psychiatry 55, 1105-1112.

Solanto, M.V., 1990. The effects of reinforcement and response-cost on a delayed response task in children with attention-deficit hyperactivity disorder: a research note. Journal of Child Psychology \& Psychiatry 31, 803-808. 
Sonuga-Barke, E.J., Saxton, T., Hall, M., 1998. The role of interval underestimation in hyperactive children's failure to suppress responses over time. Behavioral Brain Research 94, 45-50.

Sostek, A.J., Buchsbaum, M.S., Rapoport, J.L., 1980. Effects of amphetamine on vigilance in children Journal of abnormal Child Psychology 8, 491-500.

Sykes, D.H., Douglas, V.I., Morgenstern, G., 1973. Sustained attention in hyperactive children. Journal of Child Psychology and Psychiatry 14, 213-220.

Sykes, D.H., Douglas, V.I., Weiss, G., Minde, K., 1971. Attention in hyperactive children and the effect of Ritalin. Journal of Child Psychology and Psychiatry 12, 129-139.

Van der Meere, J., Sergeant, J.A., 1988. Controlled processing and vigilance in hyperactivity: time will tell. Journal of Abnormal Child Psychology 16, 641-655.

Van Leeuwen, T.H., Steinhausen, H-C., Overtoom, C.C.E., Pascual-Marqui, R.D., van't Kooster, B., Rothenberger, A., Sergeant, J.A., Brandeis, D., 1998. The continuous performance test revisited with neuroelectric mapping: impaired orienting in children with attention deficits. Behavioral Brain Research 94, 97-110. 
